\title{
COMMISSION 34: \\ INTERSTELLAR MATTER AND PLANETARY NEBULAE (MATIÈRE INTERSTELLAIRE ET NÉBULEUSES PLANÉTAIRES)
}

\author{
Report of Meetings, 22, 23, 24, 27, 28 and 29 August 1973
}

President: F D. Kahn

22 August 1973

This was a Joint Meeting with Commissions 33 and 40, largely devoted to a discussion of galactic spiral structure.

\section{August 1973}

L. Biermann gave an invited lecture on the 'Interaction of the Interstellar Medium with the Solar System'.

There followed a brief business meeting, at which the members of the Commission

(i) approved the proposals for the next President, Vice-President and Organizing Committee;

(ii) considered various ways of reducing the cost of Union publications. Several suggestions were made and were later passed on to the General Secretary;

(iii) decided that they could not make any recommendations to the General Secretary as to the scientific priorities in range of interests of the Commission.

After the business meeting contributed papers were read by B. D. Donn, C. Heiles, P. G. Mezger, K. Nandy and T. Terzian.

\section{August 1973}

The theme of this meeting was 'Observational Data'. The invited speakers were $D . C$. Morton, on the results from the Copernicus Satellite, B. J. Robinson, on interstellar molecules, J. E. Baldwin, on interstellar electrons, J. M. Greenberg, on dust and $R$. D. Davies, on the interstellar magnetic field. $R$. L. F. Boyd also spoke, on X-ray absorption data.

\section{August 1973}

The morning meeting dealt with 'Extreme Conditions in Interstellar Space'. Invited contributions were presented by $J$. H. Oort, on the galactic centre, $H$. van Woerden, on high velocity clouds, D.P. Cox, on the effects of supernova explosions, and $M$. J. Rees, on interaction with very low frequency radiation.

The afternoon meeting was held jointly with Commissions $25,27,37$ and 40 . It dealt with galactic infra-red and microwave sources, with particular emphasis on cocoon stars.

\section{August 1973}

A meeting was held jointly with Commission 35, on the subject of 'Fragmentation and Collapse'.

\section{August 1973}

The theme of this meeting was 'The Role of instabilities in Interstellar Space' Invited speakers were L. Mestel, on MHD instabilities, D. G. Wentzel, on plasma instabilities, E. R. Capriotti, on radiation pressure induced instabilities, $D . W$ Goldsmith, on thermal instabilities and $F D$. Kahn, on Rayleigh-Taylor instabilities. 